\title{
DIGITAL ECONOMY: INFORMATION TECHNOLOGY AND TRENDS IN TOURISM
}

\author{
Maiya Suyunchaliyeva ${ }^{1,{ }^{*}}$, Nazym Shedenova ${ }^{1}$, Beket $\operatorname{Kazbekov}^{1}$, Sandygul Akhmetkaliyeva ${ }^{1}$ \\ ${ }^{1}$ Al-Farabi Kazakh National University, pr. al Farabi, 71050040, Almaty, Kazakhstan
}

\begin{abstract}
This study provides an overview of the state of tourism development over the past twenty years in the field of information technology. It is argued that the knowledge created over the past two decades can be characterized as two distinct epochs - digitalization, which reflected a common understanding of how technology has changed our society and economy, and innovation, which implies the introduction and use of new technologies to develop the industry. Knowledge development in each of these periods, the authors describe the technological environment, the dominant paradigm, major research issues, and influential disciplines and research approaches. In particular, we recognize the transfer of our view of research in the field of information technology in tourism from a predominantly marketing tool for knowledge creation due to new technological conditions such as a smartphone, unmanned aerial vehicle, wearable devices, new connectivity and large volumes of data. Finally, this study discusses possible challenges and our current views on the relationship between information technology and tourism.
\end{abstract}

\section{Introduction}

Currently, national economic systems, like the world economy as a whole, are undergoing significant transformations accompanied by a complex of interrelated changes in various directions. These transformations can be fixed and explained from the standpoint of different theoretical approaches: from N. Kondratiev's theory of "long waves" to the concept of Knowledge Economy and its followers. Transition to J. Galbraith's "new industrial society" "post-industrial society" of D. Bella is caused by change of a parity of importance of factors of manufacture, increase in knowledge of the goods and services,

\footnotetext{
*Corresponding author: maia-timur@mail.ru
} 
structural changes in world and national economies, changes in factors of competitiveness of the enterprises and the organizations. The development of technologies in the field of processing and transfer of information is reflected in the innovation network approaches, in which the categories "cluster", "ecosystem", "cooperation", "shared consumption", etc. are developed.

Tourism, as one of the directions of economic development, contributes to the increase of the GDP level in the country, according to the data of the Tourism Association, the share of the level of tourism has increased by $3.9 \%$, which is about 8 trillion dollars and therefore covers 318 workplaces.

The travel and tourism (T\&T) industry plays a vital role in the global economy and society. In 2018, the industry helped generate $10.4 \%$ of global GDP and the same share in and has shown tremendous resilience over the past decade. Fostering this expansion and relative resilience is the continuing growth of the middle class in Asia and elsewhere in the world. The contribution to GDP is expected to grow by almost $50 \%$ in the next decade. [1]

While government and business will need to consider what levers they can activate to maintain or gain market share, special consideration will need to be given to maintaining tourism infrastructure, services and assets.

Modern technological changes in the field of combining telecommunications and information and computing technologies have led to the introduction of the concepts of "digital technology" and "digital economy" into scientific circulation. The latter is one of the types of economy, characterized by active introduction and use of digital technologies for storage, processing and transfer of information in all spheres of human activity. The use of digital technologies leads to the transformation of relations between economic actors in sectors such as energy, construction, banking, transport, retail, education and health care, mass media, etc.

Information technologies continue to develop our society. While many commentators have characterized the transformative power of technology in different ways, perhaps few have done so more eloquently than Nicolas Negroponte and Thomas Friedman. In his book Genesis digital (1995), Negroponte made a compelling argument for the fundamental difference between atoms that make up material things and bits that make up digital information. In so doing, he proposed a vision of what constitutes the digital medium for our future at the dawn of the Internet. About two decades later, Friedman (2016), with his book Thank You for Being Too Late: A Guide for an Optimist to Prosperity in an Age of Acceleration, presented his vision of how we should understand the 21 st century. He argued that there are three main forces, namely technology, the market and mother nature, which are all accelerating simultaneously, having a transformative effect on many important aspects of our society. He noted that 2007 was a pivotal year in that the release of the iPhone, as well as advances in hardware and software, storage, sensors and networking, had created a new reality. These ideas reflected the broad impact of information technology as well as the speed of change at the global, social level.

The importance of technology as a strategic tool for tourism was [2] with the advent of the Internet as a commercial tool, Polina Sheldon (1997) published her book on the pioneers of tourism, in which she focused on tourism as an industry of "intensive information" and illustrated its various applications in a number of related areas.

This book, together with Werner and Klein's (1999) "Information Technology and Tourism: A Complex Interconnection", published shortly afterwards, provides a new reflection on the nature of the changes brought about by it in general and on the Internet in particular, and offers a new conceptual framework for understanding structural change. Since then, the development of research in this field and tourism has spanned some twenty years. 
As we reflect on the last two decades, it is clear that we cannot separate our understanding of the relationship between tourism and tourism from a global, social view of technology. Borrowing from the ideas of Negroponte and Friedman, we can see the development of his knowledge and tourism as consisting of two different epochs: the first decade can be described as 'digitization' (1997-2006) and the second as 'the age of acceleration' (2007-2016). Although the development and diffusion of technological innovation in its infrastructure, these two epochs had their own unique technological conditions, research problems, dominant paradigms and research approaches. It is important to note that our view of technology in tourism management seems to have changed over the years. Therefore, looking back on this and tourism as an area of study, we can draw a useful conclusion about the development of our knowledge and hopefully help us to identify clues for future requests.

\section{Literature review}

The study of the theory and practice of information technologies in tourism industry are based on the works of Watkins M. [3], Akaka, M. A., \& Vargo, S. L., [4], Van der Wagen, L., \& White, L. [5] , Backman, K. F. Yeoman, I.[6] Issues of socio-economic effectiveness of digitalization in tourism industry are highlighted in the works of Battour, M., \& Ismail, M. N. , [7] Mohsin, A., [8] Nikolova, M. S., \& Hassan, S. S. [9], Buonincontri, P., Morvillo, A., Okumus, F., \& van Niekerk, M. [10], there were specific aspects in the article of researchers R.K. Sagiyeva \& Zhuparova [11] of innovation development processes in the economy of Kazakhstan. Their article discusses the need for the development of local content in terms of innovative development of the national economy of Kazakhstan.

Professors Sabden, O., \& Turginbayeva [12] wrote about innovation development processes in the economy of Kazakhstan. Their article discusses the need for the development of local content in terms of innovative development of the national economy of Kazakhstan. Professors Sabden, O., \& Turginbayeva in their research mentioned that the current stage in the formation of Kazakhstan's market economy requires the creation of an innovation policy system. In the conditions of globalization of world goods and services markets, when interdependence and interaction between different spheres of social life and activity enhanced, innovation is the foundation of the qualitative transformation of the productive capacity of the country, the process of intellectualization of the economy and raise of living standards. How innovations influence on digitalization processes in the whole, she investigates the question of increasing the innovation potential of public policy in terms of enterprises development and affected the theme of diversification innovation processes in the economy of the Republic of Kazakhstan.

Other researchers Akaka, M. A., \& Vargo, S. L., [4] wrote that they explored the role and scope of technology in value co-creation, service innovation and service systemsvalue co-creation configurations of people technology and value propositions. They argued that the consideration of technology as an operant resource in service (eco) systems provides a more encompassing view for systematically studying the way in which technologies are integrated as resources, value is collaboratively created, and service is innovated.

The study of the theory and practice of economic processes of tourism is based on the works of Van der Wagen, L., \& White, L., [5], V. K. Wells, D. G. Smith, [13]. There were specific aspects in the article of researchers Ziyadin S., Koryagina E., Grigoryan T., Tovma N., Ismail G., [14]. They researched digitalization processes in tourism industry. To achieve competitiveness in the global tourism market is possible through the development of new forms of economic integration between the state, the tourism business and the population of the country. 
Ziyadin S., [15] et al wrote that development of the tourism industry - a new approach to the development of the economy of the Republic, in achieving high results of improvement and attracting investment from the outside.

Therefore, the formation and creation of favorable conditions for the effective functioning of tourism clusters should be one of the priorities of the state tourism policy. Our state has a vast territory in which there are attractive tourist areas. However, the tourism industry of the country is characterized by an insufficient level of development. Its share in the gross domestic product is only $1.6 \%$. The development of technologies in the field of processing and transmission of information is reflected in the innovation and network approaches, in which developed the category of "cluster", "ecosystem", "collaboration", "collaborative consumption", etc.

In this connection, there is a contradiction: the main goal of diagnosing a tourism organization is to recognize the innovative potential in a timely manner, identify the influencing factors, and develop measures to activate innovative processes. Innovative management has the features of its mechanism: flexibility, adaptability, the ability to respond to the situation in a timely manner, more than usual, focused on informal management methods.

Survey of the literature and trends.

Kazakhstan, having a rich tourist and recreational potential, is characterized by an inadequate level of tourism development. Its share in GDP (only services for accommodation and food are counted) is about $0.9 \%$. In 2015, the income from tourism activities amounted to 236.4 billion KZT, which is almost 2 times more than in 2010 (126.5 billion KZT). For the last two years the GDP was increasingly grew up. The number of employees in the industry was 103.6 thousand people. The paid taxes and other obligatory payments from tourist activity to the budget of the republic amounted to 11.0 billion tenge in 2015 [16].

Information technologies play a central role in the development of the tourism industry. In the early years of mass global tourism (from the 1950s to the 1970s), computer systems were used to support the internal functions of large operators in the transport, hotel and catering sectors. The reservation systems (CRS) and global distribution systems (GDS) - Saber, Amadeus, Galileo, Worldspan and Abacus were created first by airlines and then by hotel companies to allow travel agencies (and other similar enterprises) to access timetables and prices, as well. request reservations for customers [17]. The success of the CRS and GDS paved the way for the internees, which allowed the travel and tourism industry to quickly use the hidden power.

If we will comprise the several types of tourism sphere the most preferable directions are the "relax" and "weekends". (See Figure 1). 


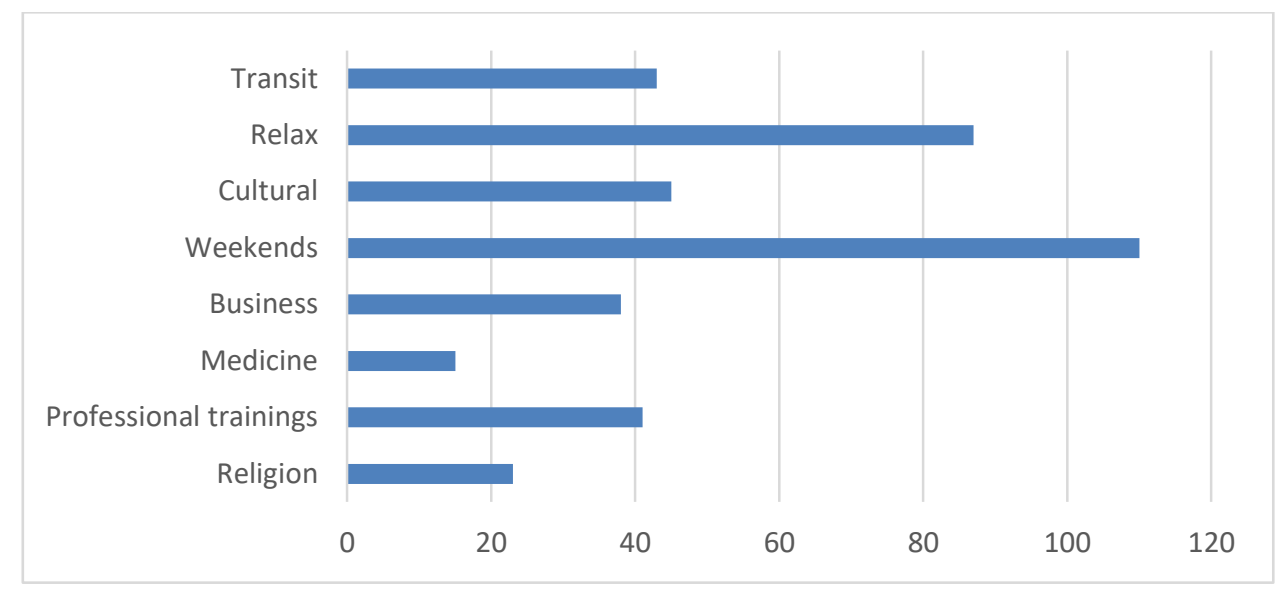

Fig 1. Preferred types of tourism in the world (made by the authors according the survey).

Today, the travel and tourism industry is one of the most significant users of Internet technologies, which has become one of the most important communication tools for travelers, as well as for tourism and tourism enterprises. The Internet application and other technological innovations have influenced tourism in various ways and have led to fundamental changes in industry structures. Tourism is an information-oriented business, the product is "self-confidence," and a preliminary comprehensive assessment of its qualities is impossible. At the time of decision making, only an abstract product model is available based on information obtained through several channels, for example, television, brochures, word of mouth or the Internet.

For example, online reservations and payment methods are used by many travel providers and consumers and have led to the emergence of tourism as one of the most important categories of e-commerce. It can be argued that the main reason for the rapid introduction of e-commerce in tourism is the close compatibility between the characteristics of tourism products and the capabilities of e-commerce applications. The importance of information technology in tourism, especially in the Web world, has increased significantly in recent years, and this trend will certainly continue. IT services have facilitated business transactions in the industry by interacting with trading partners, distributing products and providing information to consumers around the world.

In general, e-tourism has matured into a well-established sub-discipline with a few specialized organizations, journals, and conferences, as well as many research articles appearing regularly. Its organizations include Hospitality Financial \& Technology Professionals, the International Federation for Information Technologies in Travel and Tourism, and the International Hospitality Information Technology Association. Some have associated conferences and journals, such as HiTEC, the ENTER eTourism Conference, the iHITA annual conference, the Journal of Information Technology and Tourism, and the Journal of Hospitality and Tourism Technology. The sub-discipline of etourism has emerged as one of the main branches of mainstream tourism research rather than a marginal one.

Emerging e-tourism technologies and systems are always industry-driven. In the future, this area will continue its usual dynamics and paradigm shifts as new technologies are invented and widely adopted by businesses and consumers. However, many studies are post-hoc in nature, studying user adoption and behavior changes after the fact. Innovative and predictive research is needed to focus on envisioning the future and directing adoptions by working with the industry on exploring new frontiers. For example, research insights are needed on how different types of new technologies in the lab stage are relevant to the 
tourism industry, how to pick and choose different information systems, and how different online data and insights can be used to inform future operational and marketing strategies.

The tourism industry in a digital context influences various aspects in the economic sphere. Various typologies of technologies are employed in e-tourism. Consequently, three sub- areas have emerged: operational tools and systems used by tourism, hospitality businesses, or organizations to increase efficiency and competitiveness; consumer platforms adopted by tourists to search information, plan their trips, make purchases, and share experiences; and distribution and commerce tools which offer distribution channels and mediate the transactions between tourists and businesses.

Operational technologies involve many systems. A property management system is used by the accommodation sector for reservations, bookings, point of sale, phone service, housekeeping, and other services. It often interfaces with other systems such as a global distribution system, customer relationship management, revenue management, and human resources. Currently, the most popular property management system is Opera by MICROS- Fidelio [18]. A restaurant management system is used in food or drink enterprises which offers customers and employees with transactions and controls. It usually includes a point of sale, inventory and menu management, reservation and table management, and back-office functionality. Customer relationship management refers to an automated system and process. It focuses on managing customer interactions in order to increase satisfaction and maximize profits. It could be a part of a property management system or restaurant management system, or a standalone one, such as Salesforce.com. A revenue management system helps managers with market segmentation, the forecasting of customer behavior, and formulating pricing strategies for the purpose of maximizing revenue and profit.

Consumer behavior evolves along with the adoption of new developments. Many studies have been conducted on online information search through the Internet and on various information needs. These studies reveal that online resources have replaced wordof-mouth as the top information source used for gathering tourism information. Some focus on the information needs, information sources, navigational paths, and attitude changes of online tourism information search [19]. Others study the usability and accessibility of a tourism business or organization's websites. The evaluation of their design has attracted many empirical studies [20].

In addition, tourists share experiences through online platforms, and their perspectives have gained more trust than traditional marketing messages. For example, TripAdvisor.com created a shift of power between consumers and businesses. As a result, the former are more informed and the latter are becoming more transparent [21].

However, the trust may vary according to different social media platforms. As a result, social media marketing has become an emerging area to deal with positive and negative reviews and to deliver marketing messages to attract more attention.

Furthermore, in 2009 , more than $80 \%$ of US tourists will use a search engine while making travel plans. Increasing visibility on search engines includes two aspects: one, search engine optimization, refers to the practice of tweaking content on one's website and conducting link campaigns in order to reach the top positions in organic search results; another aspect, paid advertising on search engines, refers to the practice of paying for user clicks when a query is typed into a search engine and an ad is displayed along with the search results. In 2013, the three major search engines were Google, Bing, and Yahoo!, even though Yahoo! and Bing are both powered my Microsoft technology. Google and Microsoft have similar but different algorithms for ranking web pages and estimating advertising cost [22].

Lastly, the adoption of mobile technologies has changed tourists' experiences. With access to information virtually at any time and from any place, tourists can make 
plans en route, purchase products later in the planning stage, and ease the uncertainty and cultural barriers associated with tourism. Many mobile apps exist for tourists, including flight trackers, destination guides, apps from online travel agencies, and attraction guides. Mobile technologies and especially smart phones are changing the tourist experience and the ways that firms communicate and do business with their customers [23].

Distribution technologies have gone through an evolution, but many systems still co-exist today. Computer reservation systems and global distribution systems are still widely used [24]. Online travel agencies are a type of intermediary that emerged from the wide-adoption of the Internet. They offer a vast range of tourism services from airlines, hotels, car rentals, events, and activities. Tourists can also freely bundle different products together. Some were created by software companies. For example, Expedia.com was created by Microsoft Corporation and later spun off as an independent company. Travelocity was an extension of Sabre, a global distribution system. Orbitz was started as a partnership among multiple airlines in the United States in an effort to gain an advantage over then newly appeared online travel agencies such as Expedia or Travelocity.

One unique online travel agency is Priceline, which specializes in a "name your own price" system. In this system, tourists can specify the price of hotel rooms, airline seats, or other services they are looking for, along with the service level and the approximate location. The matching businesses then decide whether or not to accept the offer. The tourists are not able to see the exact brand and location of the business until the transaction is complete.

Meta-search engines are aggregates of multiple online agencies and services, such as Kayak.com and Bing.com/travel. The meta-search engine Kayak.com allows the searching of hundreds of websites at once and, thus, offers more choices. Users are then directed to the specific website they have selected to finish the transactions. As such, online commerce and social media have facilitated the sharing of tourism services and experiences, leading to new business models involving peer-to-peer communication. Airbnb.com and Couchsurfing.com are two among many. They exemplify the mix of mediation and distribution systems with customer involvement and co-creation.

The wide use of ICT by tourism businesses and tourists generates a large amount of data from information searches, transactions, and spatial movement. Today's tourists will likely carry many technology gadgets and use them to interact with ICT resources. A tourist will generate and contribute a tremendous amount of data, including data points in a tourism website's analytics data, a hotel mobile app's log data, call center logs, the amount of traffic at a destination, the sales records of tourism services, search engine query volumes, social media mentions, location data from cell phones, GPS and photos, etc. All of these are potential indicators of a tourist's likes and dislikes, motivations, planning behavior, and actual stay experiences.

This era was known for the development and maturity of the Internet as a commercial tool. In this era, technical terms such as the World Wide Web, LAN, Netscape Navigator, IE, web pages, e-mail, desktops, laptops, mobile phones and e-commerce became home names. This era can be described as digitization, as much of the online information, especially in the early years, can be seen as a digital version of existing offline content. The Internet business domain went through an early development, followed by a bubble of e-commerce, followed by a period of reflection and recovery. At the individual level, the introduction and use of the Internet was a huge shift from traditional media to a hypertext environment, resulting in cognitive dissonances and behavioral problems. While tools such as search engines are gaining in importance, the dominant mode of interaction with the Internet is reflected in metaphors such as "surfing the Internet" and "navigation", which imply that the way we searched and processed information on the Internet is fundamentally different from the past (e.g., reading a book or watching television). Thus, 
the main problem of the research can be considered as presenting tourism on the Internet. On the one hand, we noted and admired this new form of interactive tools, which seemed to have unlimited possibilities to store, display and connect information in different modes, 24 hours a day, 7 days a week and all over the world. On the other hand, we have fought and tried to find reasonable approaches to overcome the offer for tourism, the product of which is intangible, heterogeneous and empirical, with travelers and tourists. This nature of tourism experience, when it comes to new digital media, requires new conceptual and technical tools to formulate and solve the problem. Not surprisingly, one of the dominant paradigms adopted by researchers and marketers in the field of tourism was the concept of experience economics, which suggests that technology can play an indispensable role in creating, producing and transferring important experiences. Another important paradigm was the "long tail" [25], which argues that technology has changed and we consider the impact of digitization on value creation. This suggests that businesses should look not only at popular products, but also at those that are typically ignored by our conventional wisdom. Our key literature on this issue and tourism has been inspired by these general ideas of value creation in the digital age. For example, the concept of tourism, as an experience, provided a conceptual basis for building a new logic and a new language in tourism information systems [26]. Web design opportunities and strategies to incorporate multimedia content, personal stories and virtual communities that seem to be necessary for aspects of a product have been widely explored.

Thus, the literature on search behavior of travelers, such as needs, sources, structures and processes, served as a conceptual basis for the study of many problems arising in the online presentation of tourism. Looking at travel and tourism as a field of application, the study was also based on several disciplines, including, among others, communication, human computer interaction (HCI) and information management systems (MIS). The literature clearly traces the application of the technology adoption model (MIS) (Davis, 1989) and its derivatives to the study of tourism adoption and development by tourism websites or other decision-making tools. The HCI approach has provided the basis for understanding behavior when travelers interact with the Internet and travel websites for important tasks such as finding information and planning a trip [27]. In addition, many of the papers presented at the ENTER eToursim conference (celebrating its 25th anniversary in early 2018) were presented from a design and engineering point of view, or from an engineering point of view, aimed primarily at providing technical solutions for making travel decisions. (See Figure 2) 


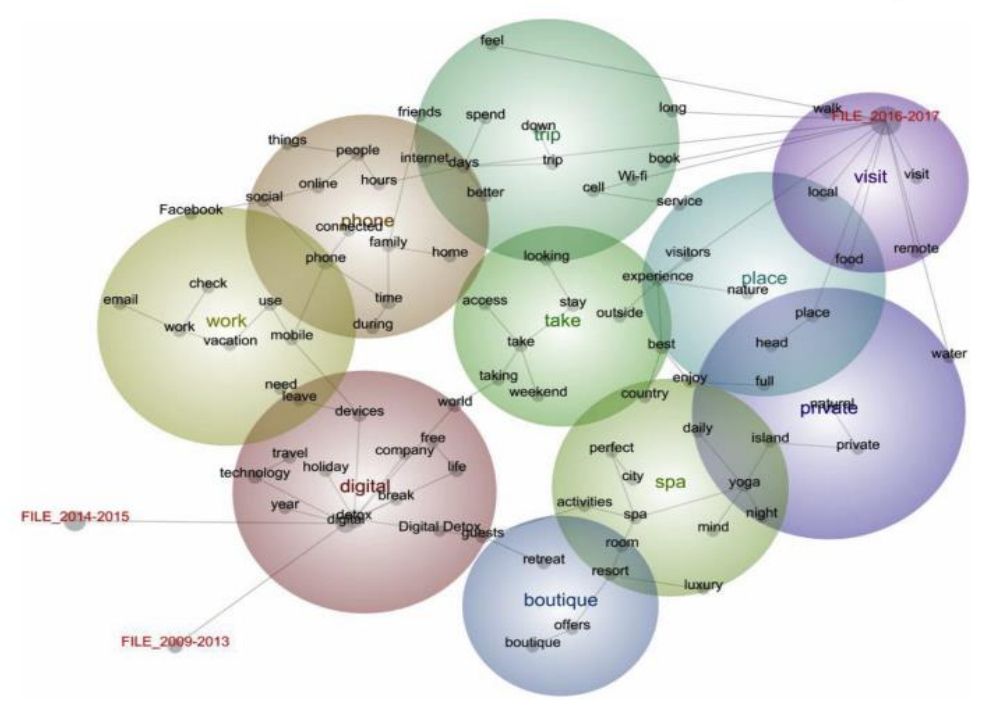

Fig 2. Changes in media's production and interpretation of DFT discourses

Source: World Tourism Organization. UNWTO Annual Report 2017// UNWTO, Madrid. DOI: // https://doi.org/10.18111/9789284419807

Changes in time in the way the media represented Digital Free Tourism (DFT) are detected with Leximancer time-based analysis. Both the evolutionary conceptualization of DFT as well as the changes in socio-cultural contexts have been visualized in the Fig. 2 and those outstanding concepts that characterized each period.

Three hundred and eighty-seven documents were used in the analysis, and time stamps were used in the figure to determine the relationship between time period and concepts. The relationship becomes stronger when the time stamp is placed closer to the theme/concept. From comparative time data, it can be seen that articles published in the first two stages are more closely related to themes that form the basis of the digital lifestyle (digital, work, telephone). The discussions of recent years are more relevant to the themes and concepts that make up the DFT experience (visit, trip, privacy, place). In addition, the first stage was located closer to the theme "boutique", which characterized the first types of digital holiday detoxification.

In this era, technology was mainly seen as a tool, a tool and an object. The main objective of the study was to understand and improve its utilities for communication and interaction with consumers, and thus it was driven by the needs of tourism marketing and business opportunities. The research dictionary was adapted for several disciplines and for foreign tourism. As in the usual literature on consumer behaviour, many of the published studies concerned the user's attitude towards acceptance and the intention to use this or that technology in the context of the installation. The role of technology has evolved from an early focus on functionality and usability, from a means of online communication and persuasion, to finally a clever being who seems to understand the personal needs, desires and wishes of travelers. It is important to note that we have seen the development of knowledge from a single theoretical or methodological approach to the culmination of a multidisciplinary approach that included CS, HCI, MIS and marketing in order to formulate our main research objectives in online tourism marketing [28]. He and ETourism as a field of research has proven itself in an increasing number of publications in leading travel magazines as well as in specialized shops such as the "Journal of Information Technology 
and Technology" Tourism, dedicated to the development and theoretical understanding of information technology primarily in the consumer environment.

Tourism and hospitality are also digitized and its services are automated. As noted in the report "Hotels of the Future", prepared on the basis of Hotels.com research and published in 2016, digital technologies automate the following areas of tourism services: automated selection of tours according to the individual needs of a particular client; technologies for face recognition during check-in, service and check-out; room management by gestures and voice, etc. The use of robots in the hotel business allows to significantly reduce personnel and automate the work of the hotel as a whole.

This era was marked by such technologies as Wi-Fi, search engines, Web 2.0, tablet, smartphone, portable computers, sensors, Internet of things, crowdsourcing, open source, drones, as well as the emergence of machine learning and artificial intelligence, etc. This era can be characterized as an era of acceleration, largely due to the huge growth of usergenerated content on the Internet, as well as the widespread adoption of technologies and devices not only in our homes and offices, but also in many other physical environments. This has resulted in the accumulation of data and information at an exponential rate. While digital divisions existed in many ways, the introduction of the Internet in developed countries has achieved saturation with different demographics. Unlike in the previous era, user access to information about the Internet had shifted from navigation to search and subscription modes. Social networks such as Facebook, Twitter and Instagram, and many other interaction tools, have helped to redefine the role of the Internet, from a publishing platform to an interaction platform and social networks. By creating new ways to connect power and demand, new business innovations, such as the collaborative economy, have emerged that have destroyed many industries. Information technology, materials or intangible values seem to be embedded in every fabric of our social and economic spheres, including travel and tourism.

\section{Methodology}

Statistical and economic analysis was used as sources of secondary information. FAO reports for 2019 and 2020 years on tourism industry directly were received and analyzed. For comparative analysis, we used the works of various scientists on innovations in tourism and ICT in the future.

\section{Results and Discussion}

In this era, technology was mainly seen as a tool, a tool and an object. The main objective of the study was to understand and improve their tools for communicating and interacting with consumers, and thus it was driven by tourism marketing needs and business opportunities. The research dictionary was adapted for several disciplines and for foreign tourism. As in the usual literature on consumer behaviour, many of the published studies concerned the user's attitude towards acceptance and the intention to use this or that technology in the context of the installation. The role of technology has evolved from an early focus on functionality and usability, from a means of online communication and persuasion, to finally a clever being who seems to understand the personal needs, desires and wishes of travelers. It is important to note that we have seen the development of knowledge from a single theoretical or methodological approach to the culmination of a multidisciplinary approach that included CS, HCI, MIS and marketing in order to formulate our main research objectives in online tourism marketing [28]. He and ETourism as a field of research has proven itself in an increasing number of publications in leading travel magazines as well as in specialized shops such as the "Journal of Information Technology 
and Technology" Tourism, dedicated to the development and theoretical understanding of information technology primarily in the consumer environment.

Tourism and hospitality are also digitized and its services are automated. As noted in the report "Hotels of the Future", prepared on the basis of Hotels.com research and published in 2016, digital technologies automate the following areas of tourism services: automated selection of tours according to the individual needs of a particular client; technologies for face recognition during check-in, service and check-out; room management by gestures and voice, etc. The use of robots in the hotel business allows to significantly reduce personnel and automate the work of the hotel as a whole.

This era was marked by such technologies as Wi-Fi, search engines, Web 2.0, tablet, smartphone, portable computers, sensors, Internet of things, crowdsourcing, open source, drones, as well as the emergence of machine learning and artificial intelligence, etc. This era can be characterized as an era of acceleration, largely due to the huge growth of usergenerated content on the Internet, as well as the widespread adoption of technologies and devices not only in our homes and offices, but also in many other physical environments. This has resulted in the accumulation of data and information at an exponential rate. While digital divisions existed in many ways, the introduction of the Internet in developed countries has achieved saturation with different demographics. Unlike in the previous era, user access to information about the Internet had shifted from navigation to search and subscription modes. Social networks such as Facebook, Twitter and Instagram, and many other interaction tools, have helped to redefine the role of the Internet, from a publishing platform to an interaction platform and social networks. By creating new ways to connect power and demand, new business innovations, such as the collaborative economy, have emerged that have destroyed many industries. Information technology, materials or intangible values seem to be embedded in every fabric of our social and economic spheres, including travel and tourism.

\section{Conclusion}

Research in this field and tourism has reflected a common understanding of how technology is changing our society and economy. In this very short period, our understanding of information technology in relation to tourism has evolved from a marketing tool to a knowledge-based creation tool. Technology comes and goes, and there will always be innovations and breakthroughs that challenge our predictions. However, what has happened over the past two decades may indicate what can happen in the tourism sector, at least in the near future.

Imagine a world in which drivers without a driver move through the streets and highways and robots provide services in our homes, offices, hotels, restaurants and tourist attractions; a world in which people are connected to each other through various portable and even built-in devices, tangible and intangible networks in a seamless, permanent and ubiquitous way; and a world in which there is no technical border between them because of our ability to represent and imitate the tourist experience. These are likely scenarios, and some of them become part of reality as we speak. For example, much of the information on the Internet today is generated by computer programs based on artificial intelligence. With these scenarios on the horizon there will be many new challenges related to how people interact with data, networks and machine intelligence. It will be interesting to understand how technologies help and shape the search and solution of tourist information [29]. Interest will be shown in developing intelligent systems that best serve tourists in tourist destinations. Beyond these practical issues, technology will continue to help us interpret and possibly redefine what it means to be a tourist [30]. In this way, information technology will remain an important and fascinating topic in tourism research. 
In the near future, research related to tourism management is likely to be related to the opportunities and challenges posed by the steady growth of data and information. It is clear that the problems and challenges related to the quality, reliability and ethics of big data applications, social knowledge and machine intelligence are largely related to travel and tourism, which will give us new space for the imagination and a new space for the imagination of the future. Perhaps it is time to broaden our research into consumer demand and tourism to include a broader conversation with a new focus on how technology can be used to achieve quality of life, economic prosperity, social well-being and sustainability. Perhaps we also need to rethink, and even challenge, some long-established ideas about the relationship between it and tourism. With the ubiquity of computing and connectivity, modern technology is no longer simply an object or tool of "e-tourism". It has joined our daily life and travel and has perhaps become "amorphous". Since open data and general social knowledge provide the basis for tourism experiences and new mechanisms of innovation, modern tourism is not only an information field. It is fair to say that information is the fabric of tourism, and tourism management is inseparable from information technology.

\section{References}

1. World Tourism Organization, UNWTO Annual Report 2017, UNWTO, Madrid. DOI: https://doi.org/10.18111/9789284419807 (2018)

2. Poon, Auliana. Tourism, technology and competitive strategies. $\mathrm{CAB}$ international, 1993.

3. Watkins M., Ziyadin S., Imatayeva A., Kurmangalieva A., Blembayeva A. Digital tourism as a key factor in the development of the economy // Economic Annals-XXI, 169(1-2), 40-45 (2018)

4. Akaka, M. A., \& Vargo, S. L. Technology as an operant resource in service (eco) systems. Information Systems and e-Business Management, 12(3), 367-384. (2014).

5. Van der Wagen, Lynn. Event management. Pearson Higher Education AU, 2010.

6. Backman, K. F. Diversification management research: The focus today and in the future. Tourism management perspectives, 25, 169-171. (2018).

7. Ziyadin, S., Madiyarova, A., Blembayeva, A. International tourism as a factor of world development, Proceedings of the 32nd IBIMA , Pages 5846-5853 (2018)

8. Mohsin, A., Ramli, N., \& Alkhulayfi, B. A. Halal tourism: Emerging opportunities. Tourism Management Perspectives, 19, 137-143. (2016).

9. Nikolova, M. S., \& Hassan, S. S. (2013). Nation branding effects on retrospective global evaluation of past travel experiences. Journal of Business Research, 66(6), 752758.

10. Buonincontri, Piera, Alfonso Morvillo, Fevzi Okumus, and Mathilda van Niekerk. "Managing the experience co-creation process in tourism destinations: Empirical findings from Naples." Tourism Management 62 (2017): 264-277.

11. Sagiyeva, R., \& Zhuparova, A. The development of local content in terms of innovative development of the national economy. World Applied Sciences Journal, 25(11), 15781581. (2013).

12. Ziyadin, S., Suieubayeva, S., Utegenova, A. Digital Transformation in Business //Lecture Notes in Networks and Systems 84. P. 408-415 (2020)

13. Wells, Victoria K., Diana Gregory Smith, Babak Taheri, Danae Manika, and Clair McCowlen. "An exploration of CSR development in heritage tourism." Annals of Tourism Research 58 1-17. (2016):

14. Ziyadin S., Koryagina E., Grigoryan T., Tovma N., Ismail G. Specificity of using information technologies in the digital transformation of diversification tourism // 
International Journal of Civil Engineering and Technology (IJCIET) Volume 10, Issue 01, January, pp. 998-1010, 2019

15. Ziyadin, Sayabek, Oleg Litvishko, Marina Dubrova, Gulzhihan Smagulova, and Maiya Suyunchaliyeva. "Diversification tourism in the conditions of the digitalization." International Journal of Civil Engineering and Technology 10, no. 2 1055-1070. (2019)

16. World Travel and Tourism Council (WTTC) Travel and Tourism economic impact 2016. Retrieved from https://www.wttc.org/-/media/files/reports/ economic\%20impact\%20research/regions\%202016/world2016.pdf (2016).

17. Carrier (2016). Indulge in the ultimate digital detox. Retrieved from https://www.carrier.co.uk/collections/black-hole-holidays/.

18. Tegmark, Max, Michael A. Strauss, Michael R. Blanton, Kevork Abazajian, Scott Dodelson, Havard Sandvik, Xiaomin Wang et al. "Cosmological parameters from SDSS and WMAP." Physical review D 69, no. 10 (2004): 103501.

19. Pan, Bing, and Daniel R. Fesenmaier. "Online information search: vacation planning process." Annals of Tourism Research 33, no. 3 809-832. (2006):

20. Law, Rob, Shanshan Qi, and Dimitrios Buhalis. "Progress in tourism management: A review of website evaluation in tourism research." Tourism management 31 , no. 3 p. 297-313. (2010)

21. Litvin, Stephen W., Ronald E. Goldsmith, and Bing Pan. "Electronic word-of-mouth in hospitality and tourism management." Tourism management 29, no. 3 (2008): 458-468.

22. Pan, Bing, Zheng Xiang, Rob Law, and Daniel R. Fesenmaier. "The dynamics of search engine marketing for tourist destinations." Journal of Travel Research 50, no. 4 (2011): 365-377.

23. Wang, Dan, Sangwon Park, and Daniel R. Fesenmaier. "The role of smartphones in mediating the touristic experience." Journal of Travel Research 51, no. 4 (2012): 371387.

24. Collins, G. R., C. Cobanoglu, and T. Malik. "Hospitality Information Technology: Learning How to Use It, Kendall." (2008).

25. Anderson, Benedict. Imagined communities: Reflections on the origin and spread of nationalism. Verso books, 2006.

26. Gretzel, Ulrike, and Daniel R. Fesenmaier. "Building narrative logic into tourism information systems." (2002): 59-61.

27. Pan, Bing, and Daniel R. Fesenmaier. "Online information search: vacation planning process." Annals of Tourism Research 33, no. 3 (2006): 809-832.

28. Xiang, Zheng, Karl Wöber, and Daniel R. Fesenmaier. "Representation of the online tourism domain in search engines." Journal of Travel Research 47, no. 2 (2008): 137150.

29. Loganatan, N., Ahmad, N., Mursitama, T. N., Taha, R., Mardani, A., \& Streimikiene, D. Economics \& Sociology, 12(3), 86-97. (2019).

30. Mkono, Muchazondida, and John Tribe. "Beyond reviewing: Uncovering the multiple roles of tourism social media users." Journal of travel research 56, no. 3: 287-298. (2017) 